\title{
A Continuity of X-Chromosome Silence from Gamete to Zygote
}

\author{
K.D. HuYNH AND J.T. LEE \\ Howard Hughes Medical Institute, Department of Molecular Biology, Massachusetts General Hospital, and \\ Department of Genetics, Harvard Medical School, Boston, Massachusetts 02114
}

\begin{abstract}
A PROBLEM OF DOSAGE
In all biological systems, gene expression is exquisitely controlled. The cell devotes vast resources to ensure that a given gene is expressed not only at the proper time but also at the appropriate level. Inappropriate or ectopic dosages often have grave consequences that cause developmental delay and organism death, as illustrated by disorders in human embryos with chromosome aneuploidies (e.g., Down's Syndrome in trisomy 21). In this regard, a problem faced by many sexually dimorphic organisms is coping with differences in sex-linked gene content arising from how sex is determined. In mammals, for example, sons (XY) inherit one $\mathrm{X}$ and one $\mathrm{Y}$ chromosome from their parents, while daughters (XX) inherit two X chromosomes (for review, see Zarkower 2001). Thus, female embryos have twice as much X-chromosome dosage as
\end{abstract} do male embryos. To deal with this dosage inequality, different organisms have evolved unique strategies (for review, see Cline and Meyer 1996; Park and Kuroda 2001). In the fruit fly (Drosophila melanogaster), the male $\mathrm{X}$ is hypertranscribed. In the round worm (Caenorhabditis elegans), expression from the two X's is reduced equally in the female. In mammals, one of the two $\mathrm{X}$ chromosomes is transcriptionally silenced through a process known as "X-chromosome inactivation" (XCI) (Lyon 1961). In all three organisms, dosage compensation is essential for proper development and the failure to achieve it results in early embryonic loss (Marahrens et al. 1997; Lee 2000; Sado et al. 2001; for review, see Cline and Meyer 1996).

Despite its essential nature, dosage compensation is apparently not necessary during the earliest stages of development. In the fruit fly and worm, dosage compensation does not take place until the blastoderm and 40-cell stages, respectively (Franke et al. 1996; Meyer 2000). In these systems, sex determination and dosage compensation are jointly regulated by the $\mathrm{X}$-to-autosome ratio, so that equalizing any differences in X-chromosome dosage may not be desirable from the outset of development. In mammals, it is also thought that XCI does not take place until the implantation period. Because zygotic gene activation (ZGA) takes place almost immediately after fertilization in the mouse, this belief suggests that the first several cell divisions of the zygote proceed in the presence of a twofold imbalance of several thousand X-linked genes between males and females. Yet, unlike in the fruit fly and worm, mammalian sex is not determined by X-to-autosome dosage (Zarkower 2001). How and why, then, does the early mammalian embryo tolerate major deviations from normal gene dosage, especially given that key developmental decisions, such as the determination of the anatomic axes and formation of specific cell lineages, are made during early development?

Recent inquiries into this problem have led to some surprising and somewhat conflicting findings (Huynh and Lee 2003; Okamoto et al. 2004). Here, we will focus on recent developments in the understanding of when and how dosage compensation occurs in the mammal and also highlight major differences in current thinking.

\section{TWO FORMS OF X-CHROMOSOME INACTIVATION IN THE MOUSE}

XCI can take on two forms. In 1961, Mary Lyon described a form of silencing in which either $\mathrm{X}$ chromosome in a female cell can be selected for silencing (Lyon 1961), thus rendering every female a mosaic of cells expressing either the paternally or maternally inherited $\mathrm{X}$ chromosome. The random form of XCI is observed in somatic tissues of eutherian mammals such as humans and mice. In 1971, Sharman and colleagues documented one of the earliest examples of genomic imprinting in mammals when they described a form of XCI in which the paternal $\mathrm{X}$ chromosome $\left(\mathrm{X}^{\mathrm{P}}\right)$ is preferentially silenced (Sharman 1971). Imprinted XCI takes place in the extraembryonic tissues of some eutherians such as the rodent (Takagi and Sasaki 1975) and cow (Xue et al. 2002). (In humans, the status of XCI in the placenta remains controversial [Ropers et al. 1978; Migeon and Do 1979; Zeng and Yankowitz 2003].) Interestingly, imprinted XCI can be traced back to some of the earliest mammals (metatherians), including the kangaroo and the opossum. This fact has led to the popular view that XCI evolved as an imprinted phenomenon, which was later modified in eutherians to a random mechanism (Graves 1996).

In support of this idea, imprinted and random XCI involve similar control elements in the mouse. Both are controlled by a cis-acting X-inactivation center (Xic) (Brown et al. 1991), a region that contains several noncoding RNA genes including Xist (Brockdorff et al. 1992; Brown et al. 1992) and the complementary Tsix gene (Lee et al. 1999). During imprinted XCI, silencing is associated with the spread of Xist RNA along the paternal X chromosome (Mak et al. 2002; Huynh and Lee 2003), while activity on the maternal $\mathrm{X}$ chromosome is preserved by expression of Tsix (Lee 2000; Sado et al. 2001). Random XCI is also ini- 
tiated by Xist expression and blocked by Tsix. One key difference is that, because random XCI is not predetermined by parental choice, this form has the added complexity of incorporating an X-chromosome "counting" step, which determines whether the embryo is $\mathrm{XX}$ or $\mathrm{XY}$, and then a "choice" step, which enables each cell to select one active $\mathrm{X}(\mathrm{Xa})$ and one inactive $\mathrm{X}(\mathrm{Xi})$ in a mutually exclusive way (for review, see Avner and Heard 2001). Once established, the Xi's of the extraembryonic and embryonic tissues both take on typical characteristics of heterochromatin and exist independently in the two anatomic compartments of the developing embryo.

\section{THE CLASSICAL MODEL: TWO ACTIVE $X$ CHROMOSOMES IN THE XX ZYGOTE}

What is the ontogenic relationship between imprinted and random XCI in the early mouse embryo? For much of the past 30 years, the prevailing view has been one in which the XX zygote initiates development with two active $\mathrm{X}$ chromosomes (for review, see Grant and Chapman 1988; Jamieson et al. 1996; Heard et al. 1997; Goto and Monk 1998). It was thought that the imprints for preferential paternal $\mathrm{X}\left(\mathrm{X}^{\mathrm{P}}\right)$ silencing are laid down during gametogenesis, but that despite this silencing mark, the maternal and paternal X's are transmitted as fully active X chromosomes. Therefore, according to the conventional view, the early embryo cannot interpret the parental imprints, so that dosage compensation does not actually take place until implantation, at which point the differentiating trophectoderm lineage goes through imprinted XCI for the first time (embryonic day 3.5 [E3.5]) and the embryo proper goes through random inactivation a day or so later (E4.5-5.5) (Fig. 1; reviewed in Goto and Monk 1998).

This well-accepted view was formulated out of elegant studies from the 1970s and early 1980s. Biochemical analyses of the X-linked genes, Hprt (Epstein et al. 1978; Kratzer and Gartler 1978) and alpha galactosidase (Adler et al. 1977), indicate two peaks of expression, with a presumptive female peak at twice the activity level as compared to that of the presumptive male peak. Analyses of
DNA replication timing reveal that the two $\mathrm{X}$ chromosomes replicated synchronously in XX embryos and that asynchronous replication does not occur until the blastocyst stage (Mukherjee 1976; Sugawara et al. 1985). This result has been taken to mean that $\mathrm{X}$-inactivation does not take place prior to the blastocyst stage. Furthermore, cell differentiation studies suggest a tight linkage between XCI and the formation of the various germ lineages, events which take place around the morula-blastocyst transition (Monk and Harper 1979; Sugawara et al. 1985). Together, these studies led to the notion that female embryos initiate development with two fully active $\mathrm{X}$ chromosomes.

\section{RIPPLES IN THE CLASSICAL MODEL}

Despite its conformity to the bulk of published evidence, the classical model has not offered consistent explanations for some data in the literature. First, the model implies that mammalian embryos can tolerate a twofold imbalance of X-linked gene expression in the preimplantation embryo, despite conventional wisdom regarding the importance of dosage compensation for development (Takagi and Abe 1990; Goto and Takagi 1998, 2000). Given that preimplantation development represents a critical period of embryogenesis when the greatest demands might be placed on proper gene regulation, one naturally asks how early embryos can tolerate global dosage aberration. Relevant to this, there has been much anecdotal evidence of karyotypic instability and generally poor quality of female embryonic stem (ES) cells specific to their carriage of two active X's (in contrast, XO female ES cells rival XY ES cells in their genetic stability), further arguing for the essential nature of dosage compensation in undifferentiated cells. Moreover, if dosage compensation were truly dispensable during early development, why should XCI be required at all for the rest of development?

The two active $\mathrm{X}$ model also implies that the gametic imprint, which is laid down in the parental germ line, is essentially ignored by the early embryo and cannot be executed until the implantation stage. What is the nature of

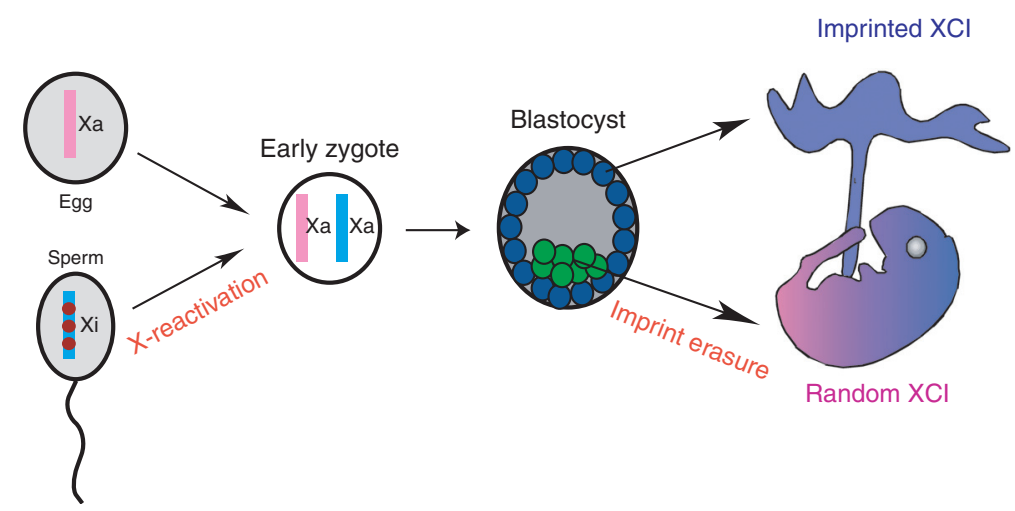

Figure 1. The classical model. In the classical model, the spermatic $\mathrm{X}$ is inactivated during spermatogenesis (indicated by red circles), but is believed to be reactivated prior to or soon after fertilization. The zygote thus maintains two active X's during preimplantation development and XCI commences for the first time with cellular differentiation at the implantation stage. It is thought that a molecular imprint(s) (e.g., DNA methylation), placed during gametogenesis, instructs cells that will form the extraembryonic tissues to undergo preferential paternal silencing (i.e., imprinted XCI), whereas cells giving rise to the embryo proper undergo imprint erasure and proceed with a random form of XCI. 
the gametic signals? In principle, the imprint can either be a repressive mark placed on $\mathrm{X}^{\mathrm{M}}$ to resist XCI or an activating mark placed on $\mathrm{X}^{\mathrm{P}}$ to induce $\mathrm{XCI}$. In fact, a cogent case can be made for the existence of both a maternal and a paternal imprint based on the results of a number of genetic manipulations. For example, $\mathrm{X}^{\mathrm{M}} \mathrm{X}^{\mathrm{M}}$ parthegenones and biparental embryos with supernumerary $\mathrm{X}^{\mathrm{M}}$, $\mathrm{s}$ $\left(\mathrm{X}^{\mathrm{M}} \mathrm{X}^{\mathrm{M}} \mathrm{Y}, \mathrm{X}^{\mathrm{M}} \mathrm{X}^{\mathrm{M}} \mathrm{X}^{\mathrm{P}}\right)$ are surprisingly resistant to inactivation of the maternally inherited $\mathrm{X}$ (Shao and Takagi 1990; Goto and Takagi 1998, 2000; Takagi 2003), suggesting that the maternal germ line supplies a protective factor to prevent the inactivation of her X chromosome. In contrast, $\mathrm{X}^{\mathrm{P}} \mathrm{X}^{\mathrm{P}}$ androgenones have a propensity to inactivate all X's of paternal contribution (Kay et al. 1994; Latham 1996; Okamoto et al. 2000), suggesting that the paternal germ line actively imprints the $\mathrm{X}$ in the opposite manner to predispose to XCI. Given that clear marks are placed on one or both X's during gametogenesis, it is difficult to explain why and how there should be a lag in executing the imprinted program until the time of implantation.

Furthermore, the classical model has been difficult to reconcile with a number of recent experimental observations made in mice. Expression studies of the housekeeping gene, $P g k 1$, and an X-linked LacZ transgene indicated that, while the maternal alleles are active during preimplantation development, the paternal alleles are repressed until the blastocyst stage (Krietsch et al. 1982; Pravtcheva et al. 1991; Tam et al. 1994; Latham and Rambhatla 1995). These findings indicated that the $\mathrm{X}^{\mathrm{P}}$ may not be uniformly active during preimplantation development. It has also been known for some time that Xist RNA can be detected at high levels at the two-cell stage (Latham and Rambhatla 1995; Sheardown et al. 1997; Matsui et al. 2001; Nesterova et al. 2001). Yet how there could be uncoupling of high Xist expression from gene silencing has never been explained satisfactorily.

In light of these discrepancies, we had previously postulated that the female mouse zygote may in fact carry an inactive $\mathrm{X}^{\mathrm{P}}$ throughout preimplantation development and that this $\mathrm{X}$ may be inherited from the father as an already silent chromosome (Huynh and Lee 2001). This hypothesis extends thinking on the evolution of dosage compensation in which it is proposed that the ancestral mechanism seen in metatherians (marsupials) is one in which imprinted $\mathrm{X}^{\mathrm{P}}$ silencing results directly from paternal germ line XY silencing (Lyon 1999; McCarrey 2001). It also extends the popular view that the nonrandom XCI pattern in the extraembryonic lineages is in part due to memory of the $\mathrm{X}^{\mathrm{P}}$ having been inactive in the male germ line (Monk and McLaren 1981) and to obvious differences in chromatin structure between the X's of the maternal germ line, where both X's are euchromatic in character, and the paternal germ line, where the XY body is heterochromatic (Grant and Chapman 1988; Jamieson et al. 1996). These latter models, however, do not explicitly invoke an inheritance model for $\mathrm{Xi}^{\mathrm{P}}$.

Thus, while the classical view has been widely accepted for much of the past 30 years, the status of the early $\mathrm{X}^{\mathrm{P}}$ was less than certain, caused in large part by the difficulty of experimentation on preimplantation mouse embryos and the lack of suitable molecular techniques for allelic expression analysis. Clearly, however, its status has been of paramount interest, as insight into the ontogeny of the $\mathrm{X}^{\mathrm{P}}$-whether it is inherited as a preinactivated $\mathrm{X}$ chromosome or instead silenced de novo in the embryo-is necessary to piece together the mechanistic details and perhaps also to drive thinking on the evolutionary sequence of X-chromosome inactivation. In the following sections, we will compare and contrast two most recent studies made possible by improvements in cytologic and genomic technologies over the past 10 years.

\section{RECENT ADVANCES: EVIDENCE FOR A SILENT $\mathrm{X}^{\mathrm{P}}$ IN PREIMPLANTATION EMBRYOS}

\section{The Preinactivation Hypothesis}

In the study by our group (Huynh and Lee 2003), two techniques were used to examine the transcriptional status of the X chromosome in preimplantation embryos. To address whether nascent transcription occurs on the $\mathrm{X}^{\mathrm{P}}$, a two-color RNA fluorescence in situ hybridization (FISH) technique was used that simultaneously detects Xist RNA and the Cot- 1 RNA fraction. Because the Cot- 1 fraction contains highly repetitive sequences that occur within the introns of unprocessed RNA, hybridization to Cot-1 probes indicate nascent transcriptional activity. The results suggest that the Xist RNA domain, which delineates the $\mathrm{X}^{\mathrm{P}}$, is coincident with a Cot- 1 "hole" and this Cot-1 exclusion is evident in XX embryos as early as the twocell stage when the first major wave of ZGA takes place (Fig. 2). The Cot-1 hole can be seen throughout preimplantation development in a vast majority of blastomeres and persists into the extraembryonic lineage, as represented by trophoblasts. This result demonstrates that the $\mathrm{X}^{\mathrm{P}}$ is transcription-poor and that this is the case essentially from the time of conception.

To examine the extent to which silencing occurs, direct analysis of gene expression was undertaken by allele-specific reverse transcriptase polymerase chain reaction (RTPCR) analysis in the morula (8-16 cells) and revealed the imperfect nature of imprinted XCI in several ways. First, imprinted XCI is imperfect at the chromosomal level. RTPCR analysis of a dozen X-linked genes revealed that, while most genes examined are subject to inactivation, genes residing at either end of the $\mathrm{X}^{\mathrm{P}}$ tend to escape silencing (Huynh and Lee 2003). Of genes subject to inactivation, the degree of silencing varies depending on the location of the gene on the $\mathrm{X}^{\mathrm{P}}$ - genes residing proximal to the Xic were subject to a higher degree of silencing than genes located more distal. The idea that $\mathrm{X}^{\mathrm{P}}$-inactivation "initiates" near the Xic and later "spreads" to the rest of the chromosome had been entertained previously (Latham 1996) and is consistent with other published studies (Singer-Sam et al. 1992; Latham and Rambhatla 1995).

Furthermore, expression is variable among blastomeres of a single embryo and among different embryos, the result of which is that $\mathrm{X}^{\mathrm{M}}$ almost never contributes $100 \%$ of transcripts for any given gene (Huynh and Lee 2003). In general, there appears to be one paternal transcript for every three to four maternal transcripts. Inter- 
A
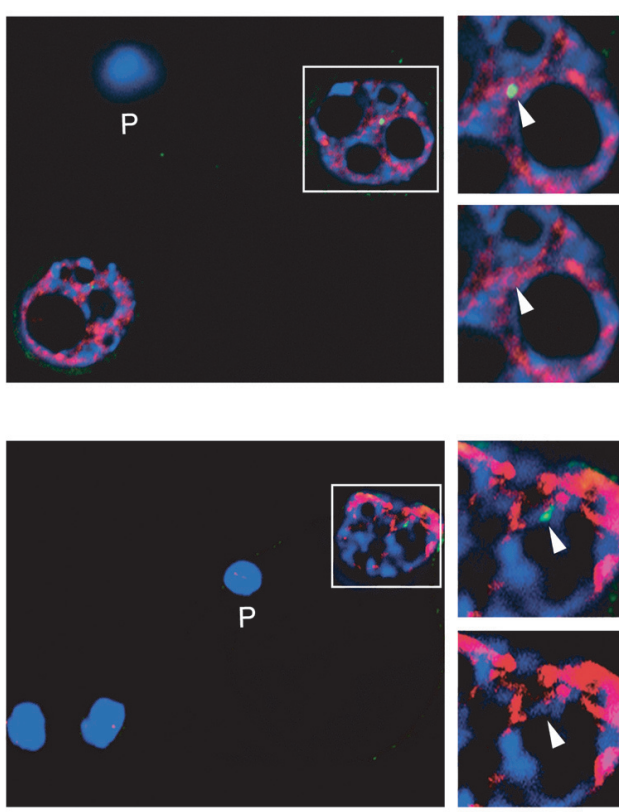

B

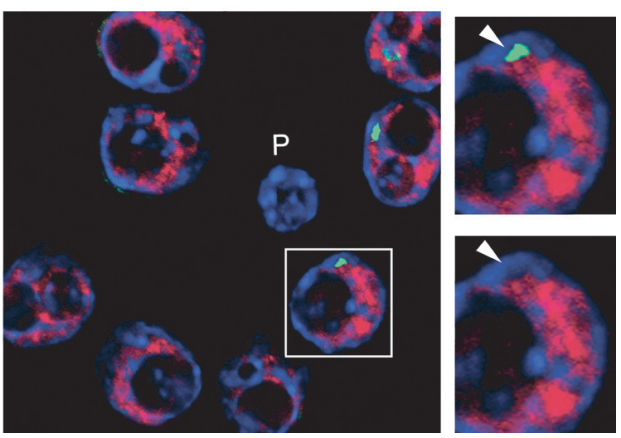

Figure 2. Transcriptional silencing of the $\mathrm{X}^{\mathrm{P}}$ is detected as early as the two-cell stage. Cot-1 RNA FISH was performed on preimplantation mouse female embryos. In this experimental technique, Cot-1 sequences are used to probe for nascent transcription in the Xist RNA domain in undenatured nuclei. The results show that, whereas Cot-1 staining (red) is detected diffusely in the nucleoplasm, a clear absence of signal is observed within the Xist RNA domain (green), indicating a lack of transcription from one of the two X chromosomes. $(A)$ Two-cellstage embryos. $(B)$ Eight-cell-stage embryo. Boxed nuclei are shown blown-up to the right; an arrowhead indicates Xist RNA domain and Cot-1 "hole." Dapi stains DNA (blue); P, polar body. (Reprinted, with permission, from Huynh and Lee 2003 [CNature Publishing Group].)

estingly, $\sim 20 \%$ of the blastomeres on average show markedly diminished or absent Xist coating as assessed by RNA FISH analysis, leading to the speculation that loss of imprinting in some blastomeres may account for a fraction of the paternal transcripts in any given embryo (Huynh and Lee 2003). Another idea worth entertaining is that blastomeres with down-regulated Xist expression might be precursors of epiblast cells. In other words, although they are initially imprinted in the zygote, some blastomeres may stochastically lose the imprint, resulting in a transient reactivation of the $\mathrm{X}^{\mathrm{P}}$ and subsequent onset of random XCI in those cells.

The inabsolute nature of preimplantation XCI is consistent with conclusions reached by other genetic experiments in the mouse. For example, it explains the occasional surviving $\mathrm{XO}$ embryo carrying the imprinted $\mathrm{X}^{\mathrm{P}}$ $\left(\mathrm{X}^{\mathrm{P}} \mathrm{O}\right)$ (Hunt 1991; Thornhill and Burgoyne 1993; Jamieson et al. 1998), the viability of some Tsix mutant mice that carry a maternally transmitted mutant allele (Lee 2000; Sado et al. 2001), and the occurrence of a small fraction of uniparental $\mathrm{X}^{\mathrm{P}} \mathrm{X}^{\mathrm{P}}, \mathrm{X}^{\mathrm{P}} \mathrm{Y}$, and $\mathrm{X}^{\mathrm{M}} \mathrm{X}^{\mathrm{M}}$ embryos with apparently normal $\mathrm{X}$-inactivation patterns (Okamoto et al. 2000; Matsui et al. 2001; Nesterova et al. 2001). We believe that the rare survivors arise from embryos in which a significant fraction of blastomeres have, by chance, a markedly weakened parental imprint that enables the embryo to use a predominantly random mechanism of XCI (for a more detailed discussion, see Huynh and Lee 2001). In light of the ability of some mutant embryos to overcome the parental imprints, imprinted XCI seems certain to be an inabsolute and reversible phenomenon.

We conclude that the preimplantation embryo is partially dosage compensated from the time of conception and propose that silencing is initiated in the paternal germ line. Importantly, this silencing mechanism is imperfect with much stochastic variation from gene to gene, blastomere to blastomere, and embryo to embryo. The lability of the silent $\mathrm{X}^{\mathrm{P}}$ during cleavage-stage development may be a required property of a chromosome that undergoes X-reactivation, the dynamic process during which Xist must be down-regulated and heterochromatin along the entire $\mathrm{X}$ be converted to euchromatin. Thus, imprinted XCI must be reversible in early development and perhaps this very need to be reversible may result in a leaky mechanism. The fact that some hallmarks of classic heterochromatin (e.g., late DNA replication timing) do not appear until the peri-implantation stage may reflect the need to prevent a permanent "lockdown" of the chromatin during cleavage stage (Huynh and Lee 2003).

Dramatic changes take place in parallel in the two compartments of the embryo at the time of implantation (see Fig. 4 below). In the extraembryonic tissues, as represented by trophoblast stem (TS) cells, the gradient of silencing along the $\mathrm{X}^{\mathrm{P}}$ disappears and all genes tested along the $\mathrm{X}^{\mathrm{P}}$ exhibit complete silencing (Huynh and Lee 2003). A more global pattern of inactivation in postimplantation cells may naturally follow from increased recruitment of heterochromatic factors such as the polycomb group proteins (Mak et al. 2002, 2004; Okamoto et al. 2004), macroH2A1 (Costanzi et al. 2000), and DNA methylation, all of which serve to "lock in" the inactive state. Thus, imprinted XCI is characterized by two distinct phases - one in the preimplantation embryo, where dosage compensation favors maternal transcription without precluding leaky paternal expression, and one in the postimplantation embryo, where the imperfection of the earlier form gives way to a globalized paternal silencing mechanism.

While those events take place in the extraembryonic lineage, the $\mathrm{X}^{\mathrm{P}}$ becomes transiently reactivated in the epi- 
blast of the embryo proper in preparation for random silencing in the soma (Huynh and Lee 2003; Mak et al. 2004). Like imprinted XCI in the placenta, random XCI is also quite complete on a per gene and chromosomal basis relative to what is seen in the preimplantation embryo. There is evidence to suggest that the partial extent of inactivation in preimplantation embryos may reflect the spreading of Xist along the $\mathrm{X}^{\mathrm{P}}$. Xist RNA only partially coats metaphase $\mathrm{X}$ chromosomes of 8- to 16-cell-stage blastomeres, whereas Xist RNA coats the entire length of the chromosome in TS and somatic cells (Matsui et al. 2001; Mak et al. 2002; Huynh and Lee 2003). While these findings imply a role for Xist, whether Xist actually plays a role in preimplantation XCI has yet to be investigated.

\section{The De Novo Inactivation Hypothesis (Okamoto et al. 2004)}

Because the study of Okamoto et al. (2004) has been laid out in detail in Heard (this volume), this section will serve only to paraphrase their main conclusions as a prelude to discussing key differences. Using a slightly different approach, Okamoto and colleagues have also reported that signs of $\mathrm{X}^{\mathrm{P}}$-inactivation are evident during cleavage stage development (Okamoto et al. 2004). By combining Xist RNA FISH and immunostaining for characteristic signatures of heterochromatin, they showed that the $\mathrm{X}^{\mathrm{P}}$ becomes increasingly enriched for histone $\mathrm{H} 3$ methylation at lysine 9 and 27, commencing at the four- to eight-cell stage and proceeding through implantation. In parallel, the polycomb group proteins, Eed and Ezh2, also show increasing recruitment to the $\mathrm{X}^{\mathrm{P}}$. Consistent with that, staining for RNA polII showed an exclusion in the Xist RNA domain, reportedly beginning at the four-cell stage and methylation at histone H3 lysine 4 (a mark of euchromatin) is largely absent throughout preimplantation development. In a significant departure from our conclusions, Okamoto et al. believe that the $\mathrm{X}^{\mathrm{P}}$ is active at least during the first two cleavage stages. This conclusion is based on RNA FISH analysis of Chicl expression, in which putative Chicl signals lie near the Xist RNA domain.

Based on expression analysis of a single gene and chromatin dynamics during cleavage stages, the authors proposed that imprinted XCI is initiated no earlier than the four- to eight-cell stage. Relevant to this conclusion, one might issue the cautionary note that the expression status of the X chromosome cannot be concluded based on analysis of a single gene, as our study demonstrates obvious stochastic fluctuations in $\mathrm{X}^{\mathrm{P}}$ repression from gene to gene, cell to cell, and embryo to embryo. Our work clearly indicates Cot-1 RNA exclusion in the $\mathrm{X}^{\mathrm{P}}$ domain at the two-cell stage. This aside, the arguments in the next section lead us to favor a silent $\mathrm{X}^{\mathrm{P}}$ from the time of conception.

\section{PREINACTIVATION VERSUS DE NOVO X-INACTIVATION}

Thus, using different approaches, the two studies both arrived at the conclusion that the mouse embryo exhibits hallmarks of dosage compensation long before implantation-a considerable shift from the prevailing view. An important difference between the recent studies, however, is that while we (Huynh and Lee 2003) observed evidence of XCI from the time of conception, Okamoto et al. believe that the $\mathrm{X}^{\mathrm{P}}$ is initially active in the zygote. This discrepancy of one- to two-cell cycles has resulted in a significant interpretive difference. Because the signature modifications to chromatin are not present before, Okamoto et al. favor the idea that XCI takes place "de novo" at the four- to eight-cell stage (for supporting arguments, see Heard, this volume). On the other hand, we observe that the Cot-1-deficient Xist RNA domain can be seen in a majority of embryos beginning at the two-cell stage, leading to the conclusion that the $\mathrm{X}^{\mathrm{P}}$ is silent from the time of conception and spurring the hypothesis that the $\mathrm{X}^{\mathrm{P}}$ may be inherited from father as a preinactivated chromosome. Several excellent, well-balanced reviews have dealt with some of these differences (Cheng and Disteche 2004; Ferguson-Smith 2004; Hajkova and Surani 2004). Our purpose, in the remaining space, is to further build the argument that motivates us to support the preinactivation model.

First and foremost, there is an apparent continuity of silence from gamete to zygote. The "preinactivation model" integrates the well-established existence of paternal germ line $\mathrm{X}$-inactivation and, according to our findings, the already silent state of the $\mathrm{X}^{\mathrm{P}}$ in the early mouse embryo. During meiotic sex chromosome inactivation (MSCI) in the paternal germ line, the synapsed $\mathrm{X}$ and $\mathrm{Y}$ chromosomes become transcriptionally silenced at the pachytene stage of prophase I (Lifschytz and Lindsley 1972). Analyses of a limited number of X-linked genes have shown that $P g k 1$, Pdhal, Hprt, Zfx, Phkal, and G6pd all remain silent in the postmeiotic sperm (Singer-Sam et al. 1990; McCarrey et al. 1992a, 2000; Hendriksen et al. 1997). Nonetheless, some genes are clearly reexpressed in postmeiotic sperm (Hendriksen et al. 1995), a fact that has been used as a counterargument to the preinactivation hypothesis (Heard 2004). However, a more detailed examination indicates that the reactivated genes, Ube1x and Ube2a, reside at a considerable distance from the Xic, notably in a region where we observed escape from silencing in preimplantation embryos. (N.B., Fmrl and Mage1/2 have also been examined, but the interpretation is complicated by the fact that Fmr 1 is not inactivated during pachytene and Mage1/2 is part of a whole family of homologous genes that may have resulted in nonspecific PCR detection [Hendriksen et al. 1995; McCarrey et al. 2002].) Thus, the postmeiotic expression pattern of the $\mathrm{X}$ actually mirrors that in preimplantation embryos (Fig. 3), further supporting the hypothesis that partial $\mathrm{X}^{\mathrm{P}}$-inactivation results from inheritance of this expression pattern from the paternal germ line.

It is also worth noting that many $\mathrm{X}$-linked genes have autosomal homologs that are expressed specifically during MSCI and in postmeiotic sperm (Dahl et al. 1990; McCarrey et al. 1992b; Hendriksen et al. 1997; Bradley et al. 2004; Emerson et al. 2004). As has been noted by others (McCarrey and Thomas 1987; Bradley et al. 2004), this phenomenon may be driven by the need to compen- 


\section{HUYNH AND LEE}

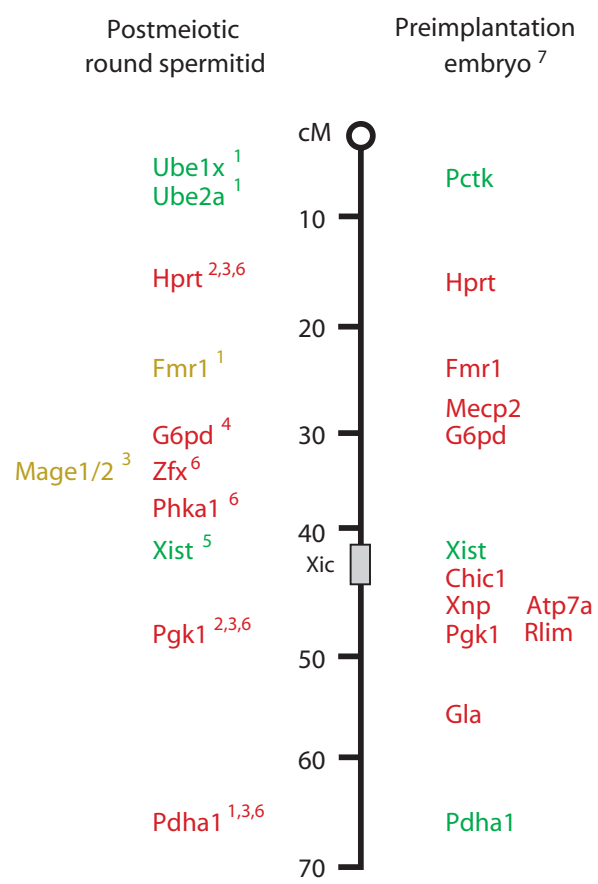

Figure 3. A continuity of $\mathrm{X}^{\mathrm{P}}$ silencing from sperm to zygote. Shown is a comparision of $\mathrm{X}^{\mathrm{P}}$ expression data in postmeiotic sperm and preimplantation embryos. Green genes, expressed; red genes, either not expressed or expression is severely reduced; yellow genes, expression not conclusive (see text). Sources: 1, Hendriksen et al. 1995; 2, Singer-Sam et al. 1990; 3, McCarrey et al. 2002; 4, Hendriksen et al. 1997; 5, McCarrey and Dilworth 1992; Richler et al. 1992; Salido et al. 1992; 6, McCarrey et al. 1992a; 7, Krietsch et al. 1982; Pravtcheva et al. 1991; Singer-Sam et al. 1992; Latham and Rambhatla 1995; Huynh and Lee 2003; Mak et al. 2004.

sate for the silencing of those X-linked genes whose continued expression is necessary throughout male meiosis. Throughout mammalian evolution, this need to compensate for MSCI may have spurred the "retrotransposition" of those genes to regions of the genome that are spared of meiotic silencing. The very existence of such X-to-autosome retrogenes indeed argues against wholesale reactivation of the $\mathrm{X}$ after male meiosis and indirectly supports the idea that the $\mathrm{X}^{\mathrm{P}}$ is propagated as a partially silent $\mathrm{X}$ after male meiosis.

It is also important to emphasize that, while we believe that imprinted XCI may trace its origins to the paternal germ line, zygotic XCI and MSCI are clearly distinct in many ways. MSCI can occur independently of an intact Xist gene (McCarrey et al. 2002; Turner et al. 2002), but our data suggest that preimplantation XCI may depend on Xist, as judged by the correlation between how far Xist RNA spreads and the extent of silencing along the $X^{P}$ (Huynh and Lee 2003). Some have argued that this apparent, though unproven, Xist dependence of zygotic XCI precludes MSCI as its origin (Heard 2004). Yet, this difference may simply reflect differences between the initiation phase of silencing through MSCI and the subsequent maintenance phase in the zygote. There is much precedent for initiation and maintenance requiring different factors. For example, while Polycomb proteins do not initiate heterochromatin formation, they are required to maintain heterochromatin once established (for review, see Francis and Kingston 2001). The preinactivation model, in fact, hypothesizes that the paternal germ line initiates X silencing in an Xist-independent fashion and that this silence is then actively maintained by the zygote, possibly through an Xist-dependent mechanism (Huynh and Lee 2003). Thus, if the recruitment of zygote-specific factors to maintain the silent $\mathrm{X}^{\mathrm{P}}$ can be called a "de novo" mechanism, then the distinction between the preinactivation and de novo models might be partly a semantic one.

The preinactivation model is also a more parsimonious solution to the ontogeny of XCI. Indeed, it simplifies the sequence of silencing by eliminating multiple rounds of inactivation and reactivation during early development as required by the de novo model. According to Okamoto et al. (2004), the first round of inactivation takes place in the male germ line (MSCI), followed by a round of reactivation in the postmeiotic spermatid, then reinactivation of the $\mathrm{X}^{\mathrm{P}}$ at the four- to eight-cell stage, followed by a second round of reactivation in the epiblast, and finally by yet another round of inactivation in the differentiating epiblast (Fig. 4). This view deviates from the conventional view only in that the second inactivation event takes place several cell cycles earlier than the blastocyst stage. In contrast, the preinactivation model posits a single initiation event in the paternal germ line through MSCI, followed by a single round of reactivation in the epiblast in preparation for random X-chromosome silencing in the soma (Fig. 4).

\section{PREINACTIVATION FROM AN EVOLUTIONARY PERSPECTIVE}

Our observations and the preinactivation model also fit neatly with various hypotheses for X-chromosome evolution in mammals. Many schemes share the proposal that the imprinted form of XCI is ancestral to the random form, based on the fact that metatherians - which predate eutherians by several million years - display an imprinted mechansim of XCI (for review, see Graves 1996). Since only female offspring inherit the $\mathrm{X}^{\mathrm{P}}$, a simple solution to the problem of dosage compensation in the early mammal would indeed have been to silence all X chromosomes of paternal origin.

This proposed evolutionary chronology is strikingly reflected in the ontogeny of XCI in the mouse, where the imprinted mechanism observed first in the cleavage stage embryo eventually gives rise to random XCI in the embryo proper (Huynh and Lee 2003). First, like marsupial XCI (Graves 1996), preimplantation XCI in the mouse shows a high degree of gene-to-gene and cell-to-cell variability and a propensity toward reactivation. Second, imprinted XCI in the mouse is biphasic, with a more localized and leaky form before preimplantation and a more globalized and complete form after implantation. Apropos to this, it has been proposed that, in its ancestral form, imprinted XCI may have been very limited in extent, perhaps involving only genes that have lost Y-chromosome homologs (Graves 1996; Lyon 1999). Later on, XCI could have spread to include more genes along the $\mathrm{X}$ 


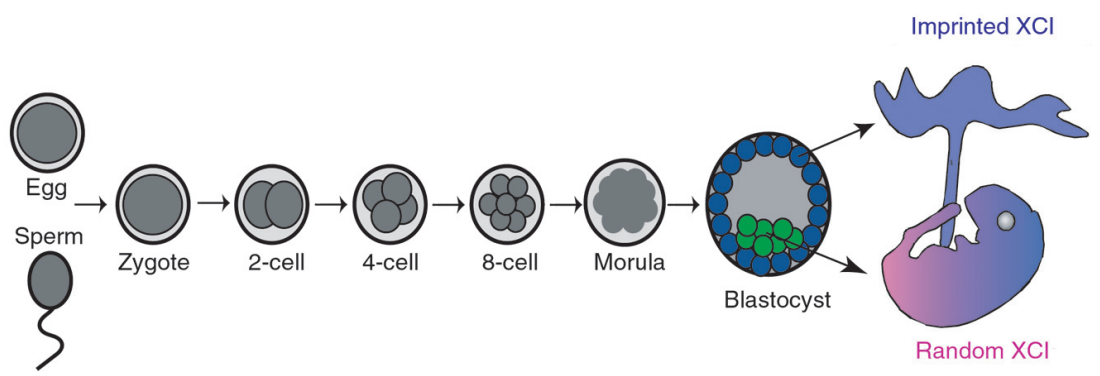

Models
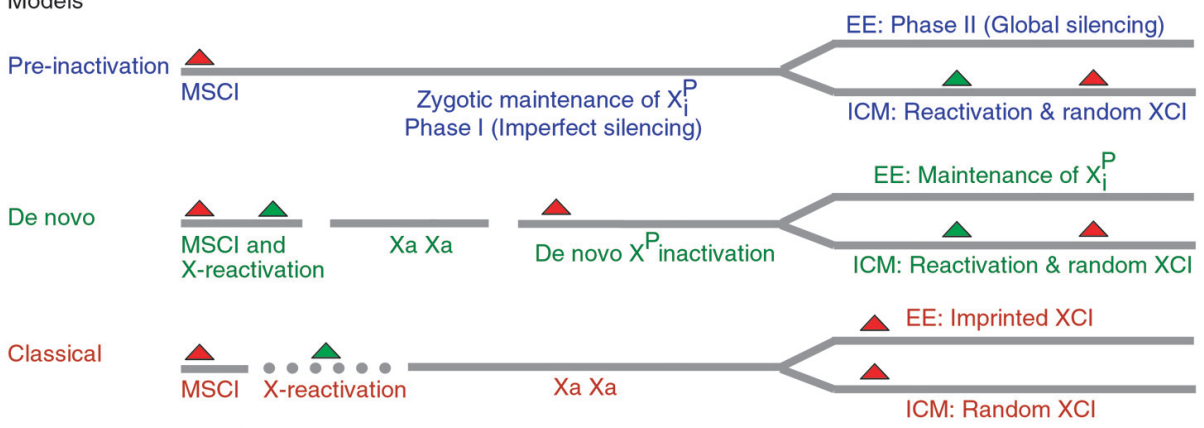

$\triangle$ Round of X-inactivation

$\triangle$ Round of X-reactivation

Figure 4. A comparison of the preinactivation, de novo, and classical models: a summary of the XCI models discussed in this review. The "preinactivation" model postulates just one round of inactivation and one round of reactivation: The female zygote inherits a preinactivated paternal $\mathrm{X}$ chromosome and maintains a partially silenced $\mathrm{X}^{\mathrm{P}}$ throughout preimplantation development (phase I). This partial inactivation gives way to a more global silencing (phase II) in extraembryonic tissues (blue circles). Epiblast cells (green circles) of the inner cell mass (ICM), on the other hand, undergo a single round of reactivation followed by a random form of XCI. In contrast, the de novo model involves many rounds of inactivation and reactivation: In this model, the paternal germ line initiates MSCI, but the X is completely reactivated after meiosis. The zygote inherits two fully active X's and begins reinactivation at the fourto eight-cell stage. In the epiblast, yet another round of reactivation takes place in preparation for a final round of inactivation in the form of random XCI. This model is very similar to the classical model, the major difference being a shift to earlier zygotic inactivation by a couple of cell cycles.

chromosome in response to a rapidly degenerating $\mathrm{Y}$ chromosome.

If ontogeny is recapitulated by phylogeny in the case of $\mathrm{XCI}$, one might ask whether the ancestral imprinted mechanism in marsupials might also involve "inheritance" of a preinactivated X chromosome from father. Indeed, others have suggested that paternal germ line $\mathrm{X}$ chromosome silencing might have been the original dosage compensation mechanism whose remnants are carried through into eutherians in the various forms we now observe (Cooper 1971; Graves 1996; Lyon 1999; McCarrey 2001). Meiotic sex chromosome inactivation with maintenance of that silent state in the zygote could have been a simple, though inefficient, system of ensuring dosage compensation in the earliest mammals. Millions of years of evolution would have provided enough time to evolve the more global and complete mechanism that we see today in eutherians.

Since MSCI is thought to be Xist independent, can we make predictions about whether there is an Xist ortholog in marsupials? To date, neither Xist nor Tsix sequences have been identified in metatherians, leading to some suggestion that marsupials may do XCI independently of Xist. On the other hand, preimplantation XCI in the mouse may require Xist (currently under testing). Given the similarities to marsupial XCI, it seems reasonable to think that the marsupial mechanism might also require Xist to inititate silencing on $\mathrm{X}^{\mathrm{P}}$ and Tsix to block it on $\mathrm{X}^{\mathrm{M}}$. Sequencing of various marsupial genomes will provide the opportunity to answer these intriguing questions.

\section{CONCLUDING STATEMENTS}

In summary, recent advances have led to a considerable departure from the traditional view by reaching the consensus that the $\mathrm{X}^{\mathrm{P}}$ is partially silent in the preimplantation mouse embryo. Thus, not only are the mechanisms of dosage compensation uniquely different among the fruit fly, worm, and mouse, but they are also different with respect to when dosage compensation takes place. Because sex determination and dosage compensation are linked by the X-to-autosome ratio in the fruit fly and the worm, it seems logical that dosage compensation would be delayed until a time when sex determination is initiated. With expressed X-linked genes playing a major role in setting up the X-to-autosome ratio, this delay in dosage compensation would enable $\mathrm{X}$-dosage differences between XX and XY/XO individuals to be "read." Since mammalian sex is primarily determined by the $\mathrm{Y}$ chromosome, the constraint on timing of dosage compensa- 
tion would not exist in the mouse. Whether other mammals show the same early XCI remains to be seen. The conclusions do raise several interesting questions: Is early XCI universally observed in mammals? If so, do they share an imprinted mechanism? In humans, several studies have strongly argued against the existence of imprinted XCI (Migeon and Do 1979; Migeon et al. 1985; Mohandas et al. 1989; Zeng and Yankowitz 2003). And, finally, how does the fruit fly or worm embryo tolerate dosage inequality between the sexes in light of the similarly essential nature of dosage compensation in those organisms?

Although further investigation into the exact timing of imprinted XCI is clearly warranted, we strongly favor the preinactivation model. Indeed, the molecular details may differ between paternal and zygotic XCI; the persistence of a partially silent X after MSCI and the later appearance of a similar $\mathrm{X}^{\mathrm{P}}$ in the zygote suggest to us a direct inheritance of an $\mathrm{Xi}$ from father to daughter. To reiterate, it is the continuity of silence that motivates us to this conclusion irrespective of the molecular means.

A final consensus must await further improvements in technology and closer examination of gene expression during the critical gamete-to-zygote transition. Two questions are of foremost relevance. First, what is the status of the X chromosome after paternal meiosis - do Xlinked genes remain silent or are they reactivated? Second, how does this pattern of expression differ from the $\mathrm{X}^{\mathrm{P}}$ profile in the two-cell embryo? The answers to these questions will have distinct implications for the mechanism and evolution of XCI and also for any molecular links to the sister phenomenon of autosomal imprinting. With the rapid pace of technological innovation, the answers to these questions will not be long in coming.

\section{ACKNOWLEDGMENTS}

We thank all members of the Lee lab for discussion. This work was funded by the National Institutes of Health (GM58839), the Pew Scholar Program, and the Howard Hughes Medical Institute.

\section{REFERENCES}

Adler D.A., West J.D., and Chapman V.M. 1977. Expression of alpha-galactosidase in preimplantation mouse embryos. $\mathrm{Na}$ ture 267: 838 .

Avner P. and Heard E. 2001. X chromosome inactivation: Counting, choice and initiation. Nat. Rev. Genet. 2: 59.

Bradley J., Baltus A., Skaletsky H., Royce-Tolland M., Dewar K., and Page D.C. 2004. An X-to-autosome retrogene is required for spermatogenesis in mice. Nat. Genet. 36: 872.

Brockdorff N., Ashworth A., Kay G.F., McCabe V.M., Norris D.P., Cooper P.J., Swift S., and Rastan S. 1992. The product of the mouse Xist gene is a $15 \mathrm{~kb}$ inactive X-specific transcript containing no conserved ORF and located in the nucleus. Cell 71: 515.

Brown C.J., Hendrich B.D., Rupert J.L., Lafreniere R.G., Xing Y., Lawrence J., and Willard H.F. 1992. The human XIST gene: Analysis of a $17 \mathrm{~kb}$ inactive X-specific RNA that contains conserved repeats and is highly localized within the nucleus. Cell 71: 527.

Brown C.J., Lafreniere R.G., Powers V.E., Sebastio G., Ballabio A., Pettigrew A.L., Ledbetter D.H., Levy E., Craig I.W., and
Willard H.F. 1991. Localization of the X inactivation centre on the human X chromosome in Xq13. Nature 349: 82.

Cheng M.K. and Disteche C.M. 2004. Silence of the fathers: Early X inactivation. Bioessays 26: 821.

Cline T.W. and Meyer B.J. 1996. Vive la difference: Males vs females in flies vs worms. Annu. Rev. Genet. 30: 637.

Cooper D.W. 1971. Directed genetic change model for X chromosome inactivation in eutherian mammals. Nature 230: 292.

Costanzi C., Stein P., Worrad D.M., Schultz R.M., and Pehrson J.R. 2000. Histone macroH2A1 is concentrated in the inactive $\mathrm{X}$ chromosome of female preimplantation mouse embryos. Development 127: 2283.

Dahl H.H., Brown R.M., Hutchison W.M., Maragos C., and Brown G.K. 1990. A testis-specific form of the human pyruvate dehydrogenase E1 alpha subunit is coded for by an intronless gene on chromosome 4. Genomics 8: 225.

Emerson J.J., Kaessmann H., Betran E., and Long M. 2004. Extensive gene traffic on the mammalian X chromosome. Science 303: 537.

Epstein C.J., Smith S., Travis B., and Tucker G. 1978. Both X chromosomes function before visible $\mathrm{X}$ chromosome inactivation in female mouse embryos. Nature 274: 500.

Ferguson-Smith A.C. 2004. X inactivation: Pre- or post-fertilisation turn-off? Curr. Biol. 14: R323.

Francis N.J. and Kingston R.E. 2001. Mechanisms of transcriptional memory. Nat. Rev. Mol. Cell Biol. 2: 409.

Franke A., Dernburg A., Bashaw G.J., and Baker B.S. 1996. Evidence that MSL-mediated dosage compensation in Drosophila begins at blastoderm. Development 122: 2751.

Goto T. and Monk M. 1998. Regulation of X chromosome inactivation in development in mice and humans. Microbiol. Mol. Biol. Rev. 62: 362 .

Goto Y. and Takagi N. 1998. Tetraploid embryos rescue embryonic lethality caused by an additional maternally inherited X chromosome in the mouse. Development 125: 3353.

2000. Maternally inherited X chromosome is not inactivated in mouse blastocysts due to parental imprinting. Chromosome Res. 8: 101.

Grant S.G. and Chapman V.M. 1988. Mechanisms of X chromosome regulation. Annu. Rev. Genet. 22: 199.

Graves J.A. 1996. Mammals that break the rules: Genetics of marsupials and monotremes. Annu. Rev. Genet. 30: 233.

Hajkova P. and Surani M.A. 2004. Development. Programming the $\mathrm{X}$ chromosome. Science 303: 633.

Heard E. 2004. Recent advances in X chromosome inactivation. Curr. Opin. Cell Biol. 16: 247.

Heard E., Clerc P., and Avner P. 1997. X chromosome inactivation in mammals. Annu. Rev. Genet. 31: 571.

Hendriksen P.J., Hoogerbrugge J.W., Baarends W.M., de Boer P., Vreeburg J.T., Vos E.A., van der Lende T., and Grootegoed J.A. 1997. Testis-specific expression of a functional retroposon encoding glucose-6-phosphate dehydrogenase in the mouse. Genomics 41: 350.

Hendriksen P.J., Hoogerbrugge J.W., Themmen A.P., Koken M.H., Hoeijmakers J.H., Oostra B.A., van der Lende T., and Grootegoed J.A. 1995. Postmeiotic transcription of X and Y chromosomal genes during spermatogenesis in the mouse. Dev. Biol. 170: 730 .

Hunt P.A. 1991. Survival of XO mouse fetuses: Effect of parental origin of the $\mathrm{X}$ chromosome or uterine environment? Development 111: 1137.

Huynh K.D. and Lee J.T. 2001. Imprinted X inactivation in eutherians: A model of gametic execution and zygotic relaxation. Curr. Opin. Cell Biol. 13: 690.

2003. Inheritance of a pre-inactivated paternal X chromosome in early mouse embryos. Nature 426: 857.

Jamieson R.V., Tam P.P., and Gardiner-Garden M. 1996. X chromosome activity: Impact of imprinting and chromatin structure. Int. J. Dev. Biol. 40: 1065.

Jamieson R.V., Tan S.S., and Tam P.P. 1998. Retarded postimplantation development of X0 mouse embryos: Impact of the parental origin of the monosomic X chromosome. Dev. Biol. 201: 13.

Kay G.F., Barton S.C., Surani M.A., and Rastan S. 1994. Im- 
printing and $\mathrm{X}$ chromosome counting mechanisms determine Xist expression in early mouse development. Cell 77: 639.

Kratzer P.G. and Gartler S.M. 1978. HGPRT activity changes in preimplantation mouse embryos. Nature 274: 503.

Krietsch W.K., Fundele R., Kuntz G.W., Fehlau M., Burki K., and Illmensee K. 1982. The expression of X-linked phosphoglycerate kinase in the early mouse embryo. Differentiation 23: 141.

Latham K.E. 1996. X chromosome imprinting and inactivation in the early mammalian embryo. Trends Genet. 12: 134.

Latham K.E. and Rambhatla L. 1995. Expression of X-linked genes in androgenetic, gynogenetic, and normal mouse preimplantation embryos. Dev. Genet. 17: 212.

Lee J.T. 2000. Disruption of imprinted X inactivation by parentof-origin effects at Tsix. Cell 103: 17

Lee J.T., Davidow L.S., and Warshawsky D. 1999. Tsix, a gene antisense to Xist at the X-inactivation centre. Nat. Genet. 21: 400.

Lifschytz E. and Lindsley D.L. 1972. The role of X chromosome inactivation during spermatogenesis (Drosophila-allocyclychromosome evolution-male sterility-dosage compensation). Proc. Natl. Acad. Sci. 69: 182.

Lyon M.F. 1961. Gene action in the X chromosome of the mouse (Mus musculus L.). Naturwissenschaften 190: 372.

1999. Imprinting and X chromosome inactivation. Results Probl. Cell Differ. 25: 73.

Mak W., Baxter J., Silva J., Newall A.E., Otte A.P., and Brockdorff N. 2002. Mitotically stable association of polycomb group proteins eed and enx 1 with the inactive $\mathrm{x}$ chromosome in trophoblast stem cells. Curr. Biol. 12: 1016.

Mak W., Nesterova T.B., de Napoles M., Appanah R., Yamanaka S., Otte A.P., and Brockdorff N. 2004. Reactivation of the paternal X chromosome in early mouse embryos. Science 303: 666.

Marahrens Y., Panning B., Dausman J., Strauss W., and Jaenisch R. 1997. Xist-deficient mice are defective in dosage compensation but not spermatogenesis. Genes Dev. 11: 156.

Matsui J., Goto Y., and Takagi N. 2001. Control of Xist expression for imprinted and random $\mathrm{X}$ chromosome inactivation in mice. Hum. Mol. Genet. 10: 1393.

McCarrey J.R. 2001. X chromosome inactivation during spermatogenesis: The original dosage compensation mechanism in mammals? In Gene families: Studies of DNA, RNA, enzymes and proteins (ed. G. Xue et al.), p. 59. World Scientific, Singapore.

McCarrey J.R. and Dilworth D.D. 1992. Expression of Xist in mouse germ cells correlates with $\mathrm{X}$ chromosome inactivation. Nat. Genet. 2: 200.

McCarrey J.R. and Thomas K. 1987. Human testis-specific PGK gene lacks introns and possesses characteristics of a processed gene. Nature 326: 501 .

McCarrey J.R., Dilworth D.D., and Sharp R.M. 1992a. Semiquantitative analysis of X-linked gene expression during spermatogenesis in the mouse: Ethidium-bromide staining of RTPCR products. Genet. Anal. Tech. Appl. 9: 117.

McCarrey J.R., Berg W.M., Paragioudakis S.J., Zhang P.L., Dilworth D.D., Arnold B.L., and Rossi J.J. 1992b. Differential transcription of Pgk genes during spermatogenesis in the mouse. Dev. Biol. 154: 160.

McCarrey J.R., Watson C., Atencio J., Ostermeier G.C., Marahrens Y., Jaenisch R., and Krawetz S.A. 2002. X chromosome inactivation during spermatogenesis is regulated by an Xist/Tsix-independent mechanism in the mouse. Genesis 34: 257.

Meyer B.J. 2000. Sex in the wormcounting and compensating X chromosome dose. Trends Genet. 16: 247.

Migeon B.R. and Do T.T. 1979. In search of non-random X inactivation: Studies of fetal membranes heterozygous for glucose-6-phosphate dehydrogenase. Am. J. Hum. Genet. 31: 581.

Migeon B.R., Wolf S.F., Axelman J., Kaslow D.C., and Schmidt M. 1985. Incomplete X chromosome dosage compensation in chorionic villi of human placenta. Proc. Natl. Acad. Sci. 82: 3390 .
Mohandas T.K., Passage M.B., Williams J.W., III, Sparkes R.S., Yen P.H., and Shapiro L.J. 1989. X chromosome inactivation in cultured cells from human chorionic villi. Somat. Cell Mol. Genet. 15: 131.

Monk M. and Harper M.I. 1979. Sequential X chromosome inactivation coupled with cellular differentiation in early mouse embryos. Nature 281: 311 .

Monk M. and McLaren A. 1981. X chromosome activity in foetal germ cells of the mouse. J. Embryol. Exp. Morphol. 63: 75.

Mukherjee A.B. 1976. Cell cycle analysis and X chromosome inactivation in the developing mouse. Proc. Natl. Acad. Sci. 73: 1608

Nesterova T.B., Barton S.C., Surani M.A., and Brockdorff N. 2001. Loss of xist imprinting in diploid parthenogenetic preimplantation embryos. Dev. Biol. 235: 343.

Okamoto I., Tan S., and Takagi N. 2000. X chromosome inactivation in XX androgenetic mouse embryos surviving implantation. Development 127: 4137.

Okamoto I., Otte A.P., Allis C.D., Reinberg D., and Heard E. 2004. Epigenetic dynamics of imprinted $X$ inactivation during early mouse development. Science 303: 644.

Park Y. and Kuroda M.I. 2001. Epigenetic aspects of X chromosome dosage compensation. Science 293: 1083.

Pravtcheva D.D., Adra C.N., and Ruddle F.H. 1991. Timing of paternal Pgk-1 expression in embryos of transgenic mice. Development 111: 1109

Richler C., Soreq H., and Wahrman J. 1992. X inactivation in mammalian testis is correlated with inactive X-specific transcription. Nat. Genet. 2: 192

Ropers H.H., Wolff G., and Hitzeroth H.W. 1978. Preferential X inactivation in human placenta membranes: Is the paternal $\mathrm{X}$ inactive in early embryonic development of female mammals? Hum. Genet. 43: 265.

Sado T., Wang Z., Sasaki H., and Li E. 2001. Regulation of imprinted X chromosome inactivation in mice by Tsix. Development 128: 1275.

Salido E.C., Yen P.H., Mohandas T.K., and Shapiro L.J. 1992. Expression of the X-inactivation-associated gene XIST during spermatogenesis. Nat. Genet. 2: 196.

Shao C. and Takagi N. 1990. An extra maternally derived X chromosome is deleterious to early mouse development. Development 110: 969

Sharman G.B. 1971. Late DNA replication in the paternally derived X chromosome of female kangaroos. Nature 230: 231.

Sheardown S.A., Duthie S.M., Johnston C.M., Newall A.E., Formstone E.J., Arkell R.M., Nesterova T.B., Alghisi G.C., Rastan S., and Brockdorff N. 1997. Stabilization of Xist RNA mediates initiation of $\mathrm{X}$ chromosome inactivation. Cell 91: 99.

Singer-Sam J., Chapman V., LeBon J.M., and Riggs A.D. 1992. Parental imprinting studied by allele-specific primer extension after PCR: Paternal X chromosome-linked genes are transcribed prior to preferential paternal $\mathrm{X}$ chromosome inactivation. Proc. Natl. Acad. Sci. 89: 10469

Singer-Sam J., Robinson M.O., Bellve A.R., Simon M.I., and Riggs A.D. 1990. Measurement by quantitative PCR of changes in HPRT, PGK-1, PGK-2, APRT, MTase, and Zfy gene transcripts during mouse spermatogenesis. Nucleic Acids Res. 18: 1255

Sugawara O., Takagi N., and Sasaki M. 1985. Correlation between $\mathrm{X}$ chromosome inactivation and cell differentiation in female preimplantation mouse embryos. Cytogenet. Cell Genet. 39: 210.

Takagi N. 2003. Imprinted X chromosome inactivation: Enlightenment from embryos in vivo. Semin. Cell Dev. Biol. 14: 319.

Takagi N. and Abe K. 1990. Detrimental effects of two active X chromosomes on early mouse development. Development 109: 189.

Takagi N. and Sasaki M. 1975. Preferential inactivation of the paternally derived $\mathrm{X}$ chromosome in the extraembryonic membranes of the mouse. Nature 256: 640.

Tam P.P., Williams E.A., and Tan S.S. 1994. Expression of an 
X-linked HMG-lacZ transgene in mouse embryos: Implication of chromosomal imprinting and lineage-specific X chromosome activity. Dev. Genet. 15: 491.

Thornhill A.R. and Burgoyne P.S. 1993. A paternally imprinted $\mathrm{X}$ chromosome retards the development of the early mouse embryo. Development 118: 171.

Turner J.M., Mahadevaiah S.K., Elliott D.J., Garchon H.J., Pehrson J.R., Jaenisch R., and Burgoyne P.S. 2002. Meiotic sex chromosome inactivation in male mice with targeted dis- ruptions of Xist. J. Cell Sci. 115: 4097.

Xue F., Tian X.C., Du F., Kubota C., Taneja M., Dinnyes A., Dai Y., Levine H., Pereira L.V., and Yang X. 2002. Aberrant patterns of $\mathrm{X}$ chromosome inactivation in bovine clones. Nat. Genet. 31: 216.

Zarkower D. 2001. Establishing sexual dimorphism: Conservation amidst diversity? Nat. Rev. Genet. 2: 175.

Zeng S.M. and Yankowitz J. 2003. X-inactivation patterns in human embryonic and extra-embryonic tissues. Placenta 24: 270. 


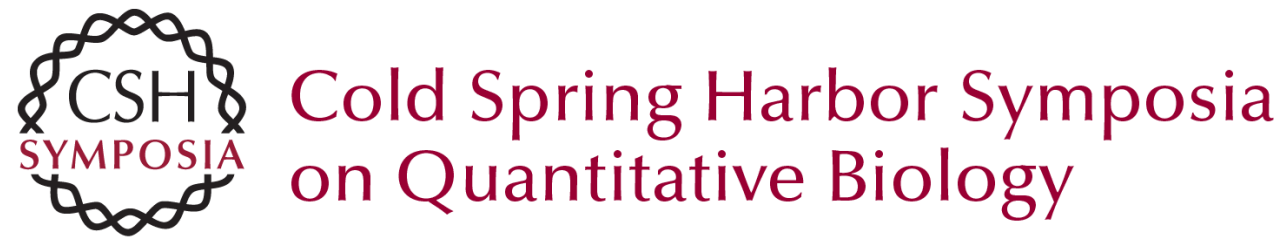

\section{A Continuity of X-Chromosome Silence from Gamete to Zygote}

K.D. HUYNH and J.T. LEE

Cold Spring Harb Symp Quant Biol 2004 69: 103-112

Access the most recent version at doi:10.1101/sqb.2004.69.103

References This article cites 81 articles, 22 of which can be accessed free at: http://symposium.cshlp.org/content/69/103.full.html\#ref-list-1

License

Email Alerting Receive free email alerts when new articles cite this article - sign up in Service the box at the top right corner of the article or click here. 